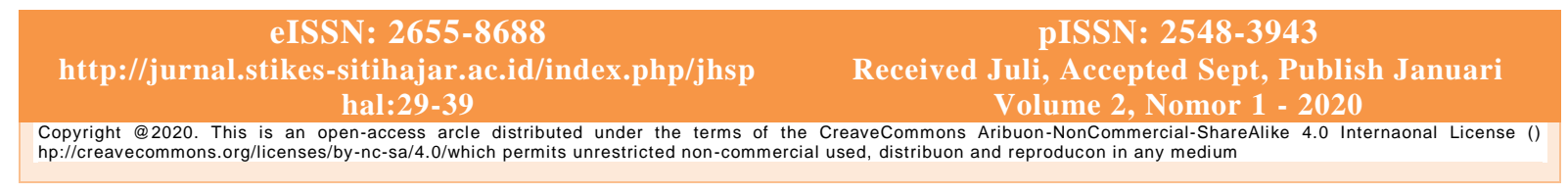

\title{
Pengaruh Pendidikan Kesehatan Tentang Posyandu Lansia Terhadap Pengetahuan dan Tindakan Pemanfaatan di Desa Ujung Rambung Kecamatan Pantai Cermin Kabupaten Serdang Bedagai
}

\author{
Purwaningsih $^{1^{*}}$ \\ ${ }^{1}$ Akademi Keperawatan Kesdam I/Bukit Barisan Medan \\ Email : purwaningsihmkm@gmail.com
}

\begin{abstract}
ABSTRAK
Jumlah lansia di Desa Ujung Rambung Kecamatan Pantai Cermin Kabupaten Serdang Bedagai sebanyak 60 orang. Dari jumlah tersebut lansia yang aktif mengikuti kegiatan lansia sebanyak 28 orang dengan jumlah laki-laki sebanyak 10 orang dan perempuan sebanyak 18 orang. Kurang aktifnya lansia diduga karena kurangnya pengetahuan, sehingga perlu diberi pendidikan kesehatan. Tujuan penelitian ini untuk mengetahui pengaruh pendidikan kesehatan terhadap pengetahuan dan tindakan pemanfaatan posyandu lansia Jenis penelitian ini adalah analitik dengan desain eksperimen semu (quasi experiment). Penelitian dilakukan di Desa Ujung Rambung Kecamatan Pantai Cermin Kabupaten Serdang Bedagai. Populasi dalam penelitian ini sebanyak 60 orang dan sampel diambil setengahnya yaitu 30 orang. Data dianalisis secara analitik dengan menggunakan uji t dua sampel berpasangan (paired sample t-test) pada taraf signifikan 0,05 . Hasil penelitian menunjukkan bahwa terdapat pengaruh (perbedaan) yang signifikan pengetahuan lansia sebelum diberikan pendidikan kesehatan (pretest) dengan pengetahuan sesudah diberi pendidikan kesehatan (posttest) dengan nilai t-hitung $=-37,622>1,699$ (t-tabel) dan nilai $\mathrm{p}=0,000<0,05$. Terdapat pengaruh (perbedaan) yang signifikan tindakan pemanfaatan posyandu lansia sebelum dan sesudah diberi pendidikan kesehatan (posttest) dengan nilai t-hitung $=-17,954>1,699$ (t-tabel) dan nilai $\mathrm{p}=0,000<0,05$. Disarankan kepada tenaga kesehatan khususnya perawat aktif untuk memberikan pendidikan kesehatan baik kepada lansia maupun kepada anggota keluarga yang tinggal satu rumah dengan lansia agar pengetahuan pasien dan keluarga bertambah serta mampu melakukan perawatan pada lansia dengan semaksimal mungkin dan mendukung lansia untuk datang ke posyandu lansia.
\end{abstract}

Kata Kunci: Pendidikan Kesehatan, Pengetahuan, Tindakan Pemanfaatan Posyandu Lansia

\begin{abstract}
The number of elderly people in Ujung Rambung Village, Pantai Cermin District, Serdang Bedagai District is as many as 60 people. Of these, there are 28 elderly who actively participate in elderly activities, with 10 men and 18 women. Underactivity of the elderly is suspected due to lack of knowledge, so it needs to be given health education. The purpose of this study was to determine the effect of health education on the knowledge and actions of elderly posyandu utilization. The type of this research is analytic with quasi experimental design. The study was conducted in Ujung Rambung Village, Pantai Cermin District, Serdang Bedagai District. The population in this study were 60 people and half of the samples were taken from 30 people. Data were analyzed analytically by using test $t$ two paired samples (paired sample $t$-test) at significance level of 0.05. Results of the study showed that t erdapat influence (difference) Significant knowledge of the elderly before being given health education (pretest) with knowledge of health education are given after (posttest) by value $\mathrm{t}$ count $=-37.622>1.699$ ( $\mathrm{t}$-table) and $\mathrm{p}=0.000<0.05$. There is a significant influence (difference) in the use of posyandu for the elderly before and after being given health education (posttest) with a value of $\mathrm{t}$-count $=-17,954>1,699$ ( $\mathrm{t}$-table) and a value of $\mathrm{p}=0,000<0.05$. It is recommended for health workers, especially active nurses to provide health education both to the elderly and to family members who live in the same house with the elderly so that the knowledge of patients and families increases and be able to take care of the elderly as fully as possible and support the elderly to come to the elderly Posyandu.
\end{abstract}

Keywords : Health Education, Knowledge, Actions for Utilization of Elderly Posyandu 


\section{Pendahuluan}

Lansia merupakan suatu kejadian yang pasti akan dialami oleh semua orang yang dikaruniai usia panjang, terjadinya tidak bisa dihindari oleh siapapun. Pada usia lanjut akan terjadi berbagai kemunduran pada organ tubuh. Namun para usia lanjut tidak perlu berkecil hati, harus selalu optimis, ceria dan berusaha agar selalu tetap perilaku sehat di usia lanjut (Ismawati, 2010).

Perilaku sehat dalam meningkatkan kesehatan lansia adalah pemeliharaan tidur untuk memastikan pemulihan fungsi tubuh sampai tingkat fungsional yang optimal dan untuk memastikan keterjagaan di siang hari guna menyelesaikan tugas-tugas dan menikmati kualitas hidup yang tinggi (Stanley, 2012). Namun sebagian besar kelompok usia lanjut mempunyai risiko mengalami gangguan pola tidur sebagai akibat pensiun, perubahan lingkungan sosial, penggunaan obat-obatan yang meningkat, penyakitpenyakit dan perubahan irama sirkadian (Prayitno, 2012).

Dampak yang mungkin terjadi pada lansia akibat kurang tidur (istirahat) antara lain mudah terkena depresi, rentan terhadap penyakit jantung, menurunkan kemampuan dalam memenuhi tugas sehari-hari dan menurunkan daya tahan tubuh (lemah, lesu, kurang bergairah, lemas) sehingga mempermudah lansia menderita penyakit seperti batuk, pilek, meriang dan demam (Putra, 2011).

Keluhan tentang kesulitan istirahat dan tidur waktu malam seringkali terjadi pada lansia. Sebagaimana contoh, seorang lansia yang mengalami arthritis mempunyai kesulitan tidur akibat nyeri sendi. Kecenderungan untuk tidur siang kelihatannya meningkat secara progresif dengan bertambahnya usia. Peningkatan waktu siang hari dipakai untuk tidur dapat terjadi karena seringnya terbangun pada malam hari. Dibandingkan dengan jumlah waktu yang dihabiskan di tempat tidur, waktu yang dipakai tidur menurun sejam atau lebih. Perubahan pola tidur pada lansia disebabkan perubahan system syaraf pusat yang mempengaruhi pengaturan tidur. Kerusakan sensorik, umum dengan penuaan, dapat mengurangi sensitivitas terhadap waktu mempertahankan irama sirkadian (Potter \& Perry, 2012).

Lansia memiliki pola tidur yang berbeda dengan remaja. Lansia yang notabene tidak melakukan banyak aktivitas fisik memerlukan tidur yang lebih sedikit dari pada remaja. Kebutuhan tidur lansia semakin menurun karena dorongan homeostatic untuk tidurpun berkurang. Pada lansia, perempuan lebih banyak mengalami insomia dibandingkan lakilaki yang lebih banyak menderita sleep apnea atau kondisi medis lainnya yang dapat mengganggu tidur (Putra, 2011).

Prevalensi sulit tidur (insomnia) pada usia lanjut di Amerika adalah 54\% untuk wanita dan $46 \%$ pada pria dan di Hongkong terdapat $10 \%$ pada usia lanjut. Seorang usia lanjut akan membutuhkan waktu lebih lama untuk masuk tidur (berbaring lama di tempat tidur sebelum tertidur) dan mempunyai lebih sedikit/ lebih pendek waktu tidur nyenyaknya (Rafknowledge, 2014).

Di Indonesia gangguan tidur menyerang sekitar 50\% orang yang berusia 65 tahun. Insomnia merupakan gangguan tidur yang paling sering ditemukan, setiap tahun diperkirakan sekitar 20\% - 50\% lansia melaporkan adanya insomnia dan sekitar 17\% mengalami gangguan tidur yang serius. Prevalensi insomnia pada lansia cukup tinggi yaitu $67 \%$ (Rafiudin, 2014).

Seorang usia lanjut akan membutuhkan waktu lebih lama untuk masuk tidur (berbaring lama di tempat tidur sebelum tidur) dan mempunyai lebih sedikit/ lebih pendek waktu tidur nyenyaknya. Orang yang sudah tua (berusia \pm 50 tahun) memerlukan waktu tidur \pm 6 jam (pukul 23.00 - 05.00 Wib) (Leniwaty, 2010).

Menurut Putra (2011) menyebutkan bahwa faktor-faktor yang dapat menyebabkan insomnia antara lain : stress atau kecemasan yang biasanya dikarenakan memikirkan 
permasalahan yang sedang dihadapi, faktor depresi karena seseorang ingin melepaskan diri dari masalah yang dihadapinya sehingga seseorang ingin tidur terus untuk menghilangkannya, faktor pola makan yang buruk dengan mengkonsumsi makanan berat sesaat sebelum tidur dapat membuat sulit tidur, dan faktor mengkonsumsi kafein, nikotin (rokok), alkohol serta kurang berolah raga. Selain itu, suasana lingkungan seperti suara bisik, suhu udara, perubahan lingkungan dan efek samping yang dihasilkan oleh obatobatan yang dikonsumsi.

Seiring dengan meningkatnya angka harapan hidup, jumlah penduduk lansia (lanjut usia) atau di atas 60 tahun diperkirakan akan meningkat. Data yang disodorkan persatuan Gerontologi Medik Indonesia, menyebutkan pada tahun 2015 jumlah lansia di Indonesia akan mencapai 36 juta orang atau 11,34\% dari populasi penduduk. Presentase angka harapan hidup ini terus pacu melalui berbagai langkah terutama di bidang kesehatan, agar kualitas lansia bisa berbanding dengan kuantitasnya. Karena usia seperti ini diharapkan tidak berarti sakit-sakitan, namun harus sehat dan produktif. Informan yang tidak memanfaatkan posyandu lansia banyak yang tidak mengetahui tentang sasaran dan posyandu lansia, sehingga mereka tidak mengetahui kalau umur mereka saat ini termasuk sasaran kegiatan posyandu lansia dan salah persepsi bahwa kegiatan posyandu lansia bukan hanya ditujukan untuk lansia perempuan dan lansia yang sakit saja. Disamping itu mereka tidak mengetahui bahwa program di posyandu lansia merupakan program pencegahan penyakit sehingga mereka menilai kegiatan tersebut kurang baik karena tidak ada pelayanan pengobatan yang dilakukan dokter. Hal ini kurangnya sosialisasi tentang posyandu lansia ke masyarakat. Pada hal pengetahuan yang baik berdampak pada meningkatnya pemanfaatan layanan posyandu lansia oleh masyarakat.

Meningkatkan pengetahuan dan pemahaman lansia salah satunya dilaksanakan melalui promosi atau pendidikan kesehatan (Depkes, 2008). Pendidikan kesehatan sebagai bagian dari kesehatan masyarakat, berfungsi sebagai media atau sarana untuk menyediakan kondisi sosio-psikologis sedemikian rupa sehingga individu atau masyarakat berperilaku sesuai dengan norma-norma hidup sehat, dengan perkataan lain pendidikan kesehatan bertujuan untuk mengubah pengetahuan, sikap dan tindakan individu atau masyarakat sehingga sesuai dengan norma-norma hidup sehat. Pendidikan kesehatan akan berpengaruh pada perilaku kesehatan, selanjutnya perilaku kesehatan akan berpengaruh kepada meningkatnya indikator kesehatan masyarakat sebagai keluaran (outcome) pendidikan kesehatan (Notoatmodjo, 2012).

Tingkat pengetahuan kader posyandu sangat penting dalam pemberian sinar infrared dan tens yang diberikan dalam kegiatan posyandu lansia di Desa Sukasari Kecamatan Pegajahan Kabupaten Serdang Bedagai sangat bermanfaat bagi lansia dalam meningkatkan kesehatan lansia (Sulaiman, Anggriani, \& Sutandra, 2019).

Puskesmas Pantai Cermin adalah salah satu puskesmas induk yang ada di Kabupaten Serdang Bedagai. Berdasarkan data yang diperoleh dari Puskesmas Pantai Cermin bahwa terdapat sebanyak 5 posyandu lansia dengan jumlah lansia sebanyak 1.400 orang terdiri dari laki-laki sebanyak 717 orang, dan perempuan sebanyak 683 orang. Jika dilihat dari keaktifan lansia mengikuti posyandu lansia maka anggota posyandu lansia yang aktif sebanyak 125 orang dengan jumlah laki-laki sebanyak 47 orang dan laki-laki sebanyak 78 orang. Pelatihan dan penyuluhan diberikan kepada kader posyandu lansia di Desa Suka raya memberikan dampak sebanyak 50\% responden memanfaatkan posyandu lansia di Desa Suka Raya Kecamatan Pancur Batu (Sulaiman \& Anggriani, 2018).

Desa Ujung Rambung merupakan satu desa yang ada di wilayah kerja Puskesmas Pantai Cermin dengan jumlah lansia terbanyak dibandingkan desa lainnya. Jumlah lansia di Desa Ujung Rambung sebanyak 60 orang. Dari jumlah tersebut lansia yang aktif mengikuti kegiatan lansia sebanyak 28 orang dengan jumlah laki-laki sebanyak 10 orang 
dan perempuan sebanyak 18 orang. Banyaknya lansia yang tidak aktif mengikuti kegiatan posyandu lansia kemungkinan disebabkan kurangnya informasi tentang posyandu lansia sehingga dirasa perlu untuk diberikan pendidikan kesehatan tentang posyandu lansia.

Berdasarkan uraian di atas peneliti tertarik untuk melakukan penelitian dengan judul: Pengaruh Pendidikan Kesehatan Tentang Posyandu Lansia Terhadap Pengetahuan dan Tindakan Pemanfaatan Posyandu Lansia di Desa Ujung Rambung Kecamatan Pantai Cermin Kabupaten Serdang Bedagai Tahun 2019.

\section{Metode Penelitian \\ Jenis Penelitian}

Penelitian ini merupakan penelitian analitik menggunakan pendekatan one group pre and post test design dengan rancangan penelitian eksperimen semu (Quasi Experiment). Rancangan penelitian dapat digambarkan sebagai berikut :

Tabel Rancangan Penelitian

\begin{tabular}{|c|c|c|c|}
\hline Kelompok & Pre Test & Perlakuan & Post test \\
\hline Eksperimen & Tes 1 & $\begin{array}{c}\text { Penkes tentang Posyandu } \\
\text { Lansia }\end{array}$ & Tes 2 \\
\hline
\end{tabular}

Tujuan penelitian ini untuk mengetahui pengetahuan responden dan pemanfaatan posyandu sebelum dan setelah diberikan pendidikan kesehatan tentang posyandu lansia di Desa Ujung Rambung Kecamatan Pantai Cermin Kabupaten Serdang Bedagai tahun 2019.

\section{Lokasi dan Waktu Penelitian}

Lokasi penelitian ini dilaksanakan di Puskesmas Pantai Cermin Kecamatan Pantai Cermin Kabupaten Serdang Bedagai tahun 2019. Penelitian ini dilakukan pada tanggal 18 Februari 2019.

Dalam penelitian ini lansia yang berumur $>60$ tahun ke atas berdomisili di wilayah kerja Puskesmas Pantai Cermin Kecamatan Pantai Cermin Kabupaten Serdang Bedagai tahun 2019 sebanyak 60 orang.

Sampel dalam penelitian ini diambil setengah dari jumlah populasi atau $50 \%$ sehingga diperoleh sampel sebanyak 30 orang.

Uji validasi yang digunakan untuk mengetahui pengetahuan dan pemanfaatan posyandu lansia sebelum dan setelah diberi perlakuan penkes kesehatan tentang posyandu lansia menggunakan dua sampel berpasangan (paired sample t-test). Uji ini digunakan untuk mengetahui ada atau tidaknya perbedaan rata-rata antara dua kelompok sampel yang berpasangan (berhubungan), maksudnya adalah sebuah sampel tetapi mengalami perlakuan (data diukur sebelum dan setelah perlakuan) (Priyatno, 2009).

Penerimaan atau penolakan hipotesis penelitian adalah sebagai berikut :

1. Ho diterima dan $\mathrm{Ha}$ ditolak, jika nilai t-hitung $<\mathrm{t}$-tabel atau nilai signifikan (probabilitas $=p)>0,05$, maka tidak ada pengaruh pendidikan kesehatan tentang posyandu lansia terhadap tindakan pemanfaatan posyandu lansia di Desa Ujung Rambung Kecamatan Pantai Cermin Kabupaten Serdang Bedagai tahun 2019.

2. Ho ditolak dan Ha diterima, jika nilai t-hitung > t-tabel atau nilai signifikan ( probabilitas $=p)<0,05$ maka ada pengaruh pendidikan kesehatan tentang posyandu lansia terhadap tindakan pemanfaatan posyandu lansia di Desa Ujung Rambung Kecamatan Pantai Cermin Kabupaten Serdang Bedagai tahun 2019. 
Hasil Penelitian

Analisis Univariat

Karakteristik Responden

Umur

Berdasarkan hasil penlitian, usia responden yang berumur 40-50 tahun sebanyak 4 orang (13,3\%), berumur 51-60 sebanyak 14 orang (46,7\%), berumur 61-70 tahun sebanyak 12 orang $(40,0 \%)$.

Tabel 1. Distribusi Responden Berdasarkan Umur di Posyandu Lansia Desa Ujung Rambung Kecamatan Pantai Cermin Kabupaten Serdang Bedagai

\begin{tabular}{|c|c|c|c|}
\hline No & Umur & Jlh & Persentase (\%) \\
\hline 1 & $60-65$ & 14 & 46,7 \\
2 & $66-70$ & 12 & 40,0 \\
3 & $>70$ & 4 & 13,3 \\
\hline \multicolumn{2}{|c|}{ TOTAL } & $\mathbf{3 0}$ & $\mathbf{1 0 0 , 0}$ \\
\hline
\end{tabular}

\section{Jenis Kelamin}

Berdasarkan jenis kelamin, responden berjenis kelamin perempuan sebanyak 22 orang $(73,3 \%)$, sedangkan responden perempuan sebanyak 8 orang $(26,7 \%)$.

Tabel 2. Distribusi Responden Berdasarkan Jenis Kelamin di Posyandu Lansia Desa Ujung Rambung Kecamatan Pantai Cermin Kabupaten Serdang Bedagai

\begin{tabular}{|c|c|c|c|}
\hline No & Jenis Kelamin & Jlh & Persentase (\%) \\
\hline 1 & Laki-laki & 22 & 26,7 \\
2 & Perempuan & 8 & 73,3 \\
\hline \multicolumn{2}{r|}{ TOTAL } & $\mathbf{3 0}$ & $\mathbf{1 0 0 , 0}$ \\
\hline
\end{tabular}

\section{Pendidikan}

Berdasarkan pendidikan, responden yang berpendidikan SD sebanyak 11 orang $(36,7 \%)$, berpendidikan SMP sebanyak 16 orang $(53,3 \%)$, dan berpendidikan SMA sebanyak 3 orang $(10,0 \%)$.

Tabel 3. Distribusi Responden Berdasarkan Pendidikan di Posyandu Lansia Desa Ujung Rambung Kecamatan Pantai Cermin Kabupaten Serdang Bedagai

\begin{tabular}{|c|c|c|c|}
\hline No & Jenis Kelamin & Jlh & Persentase (\%) \\
\hline 1 & SD & 11 & 36,7 \\
2 & SMP & 16 & 53,3 \\
3 & SMA & 3 & 10,0 \\
\hline \multicolumn{2}{|c|}{ TOTAL } & $\mathbf{3 0}$ & $\mathbf{1 0 0 , 0}$ \\
\hline
\end{tabular}

\section{Pengetahuan}

\section{Sebelum Pendidikan Kesehatan}

Berdasarkan data menunjukkan yang paling banyak dijawab "benar" adalah pertanyaan nomor 1 yaitu posyandu lansia adalah pelayanan kesehatan yang ditujukan untuk kesejahteraan orang yang lanjut usia sebanyak 23 orang $(76,7 \%)$. Pertanyaan yang banyak dijawab "salah" adalah pertanyaan nomor 10 yaitu kegiatan posyandu lansia terdiri dari 3 meja sebanyak 24 orang $(80,0 \%)$. 
Tabel 4. Distribusi Frekuensi Jawaban Tiap Butir Pernyataan Pengetahuan Lansia Sebelum Pendidikan Kesehatan di Desa Ujung Rambung Kecamatan Pantai Cermin Kabupaten Serdang Bedagai Tahun 2019

\begin{tabular}{|c|c|c|c|c|c|c|c|}
\hline \multirow{3}{*}{ No } & \multirow{3}{*}{ Pertanyaan } & \multicolumn{4}{|c|}{ Jawaban } & \multirow{2}{*}{\multicolumn{2}{|c|}{ Total }} \\
\hline & & \multicolumn{2}{|c|}{ Benar } & \multicolumn{2}{|c|}{ Salah } & & \\
\hline & & $\mathbf{f}$ & $\%$ & $\mathbf{f}$ & $\%$ & $\mathbf{F}$ & $\%$ \\
\hline 1 & $\begin{array}{l}\text { Posyandu lansia } \\
\text { kesehatan adalah pelayanan } \\
\text { kesejahteraan orang }\end{array}$ & 23 & 76,7 & 7 & 23,3 & 30 & 100,0 \\
\hline 2 & $\begin{array}{l}\text { Tujuan posyandu lansia adalah untuk } \\
\text { memelihara kesehatan lansia sesuai } \\
\text { kemampuan dan aktivitas fisik dan } \\
\text { mental. }\end{array}$ & 13 & 43,3 & 17 & 56,7 & 30 & 100,0 \\
\hline 3 & $\begin{array}{l}\text { Posyandu lansia dapat juga dimanfaatkan } \\
\text { sebagai sarana untuk menyalurkan minat } \\
\text { lansia. }\end{array}$ & 9 & 30,0 & 21 & 70,0 & 30 & 100,0 \\
\hline 4 & $\begin{array}{l}\text { Posyandu lansia hanya untuk lansia } \\
\text { perempuan saja. }\end{array}$ & 8 & 26,7 & 22 & 73,3 & 30 & 100,0 \\
\hline 5 & $\begin{array}{l}\text { Sasaran lansia yaitu penduduk yang } \\
\text { berumur } 50 \text { tahun ke atas. }\end{array}$ & 13 & 43,3 & 17 & 56,7 & 30 & 100,0 \\
\hline 6 & $\begin{array}{l}\text { Manfaat posyandu lansia untuk } \\
\text { menyalurkan minat dan bakat } \\
\text { mengisi waktu luang. }\end{array}$ & 7 & 23,3 & 23 & 76,7 & 30 & 100,0 \\
\hline 7 & $\begin{array}{l}\text { Dalam posyandu lansia dilakukan } \\
\text { penyuluhan tentang gizi untuk lansia. }\end{array}$ & 13 & 43,3 & 17 & 56,7 & 30 & 100,0 \\
\hline 8 & $\begin{array}{l}\text { Kegiatan olahraga di posyandu lansia } \\
\text { salah satunya adalah senam lansia. }\end{array}$ & 7 & 23,3 & 23 & 76,7 & 30 & 100,0 \\
\hline 9 & $\begin{array}{l}\text { Posyandu lansia merupakan upaya untuk } \\
\text { mencegah terjadinya penyakit pada } \\
\text { lansia. }\end{array}$ & 8 & 26,7 & 22 & 73,3 & 30 & 100,0 \\
\hline 10 & $\begin{array}{l}\text { Kegiatan posyandu lansia terdiri dari } 3 \\
\text { meja. }\end{array}$ & 6 & 20,0 & 24 & 80,0 & 30 & 100,0 \\
\hline
\end{tabular}

\section{1) Setelah Pendidikan Kesehatan}

Berdasarkan data menunjukkan yang paling banyak dijawab "benar" adalah pertanyaan nomor 1 yaitu posyandu lansia adalah pelayanan kesehatan yang ditujukan untuk kesejahteraan orang yang lanjut usia sebanyak 25 orang $(83,3 \%)$. Pertanyaan yang banyak dijawab "salah" adalah pertanyaan nomor 2 yaitu tujuan posyandu lansia adalah

untuk memelihara kesehatan lansia sesuai kemampuan dan aktivitas fisik dan mental dan nomor 10 yaitu kegiatan posyandu lansia terdiri dari 3 meja masing-masing sebanyak 14 orang $(46,7 \%)$ 
Tabel 5 Distribusi Frekuensi Jawaban Tiap Butir Pernyataan Pengetahuan Lansia Setelah Pendidikan Kesehatan di Desa Ujung Rambung Kecamatan Pantai Cermin Kabupaten Serdang Bedagai Tahun 2019

\begin{tabular}{|c|c|c|c|c|c|c|c|}
\hline \multirow{3}{*}{ No } & \multirow{3}{*}{ Pertanyaan } & \multicolumn{4}{|c|}{ Jawaban } & \multirow{2}{*}{\multicolumn{2}{|c|}{ Total }} \\
\hline & & \multicolumn{2}{|c|}{ Benar } & \multicolumn{2}{|c|}{ Salah } & & \\
\hline & & $\mathbf{f}$ & $\%$ & $\mathbf{F}$ & $\%$ & $\mathbf{F}$ & $\%$ \\
\hline 1 & $\begin{array}{lrcr}\text { Posyandu } & \text { lansia } & \text { adalah pelayanan } \\
\text { kesehatan } & \text { yang } & \text { ditujukan } & \text { untuk } \\
\text { kesejahteraan } & \text { orang } & \text { yang lanjut } & \text { usia. }\end{array}$ & 25 & 83,3 & 5 & 16,7 & 30 & 100,0 \\
\hline 2 & $\begin{array}{l}\text { Tujuan posyandu lansia adalah untuk } \\
\text { memelihara kesehatan lansia sesuai } \\
\text { kemampuan dan aktivitas fisik dan mental. }\end{array}$ & 16 & 53,3 & 14 & 46,7 & 30 & 100,0 \\
\hline 3 & $\begin{array}{l}\text { Posyandu lansia dapat juga dimanfaatkan } \\
\text { sebagai sarana untuk menyalurkan minat } \\
\text { lansia. }\end{array}$ & 22 & 73,3 & 8 & 26,7 & 30 & 100,0 \\
\hline 4 & $\begin{array}{l}\text { Posyandu lansia hanya untuk lansia } \\
\text { perempuan saja. }\end{array}$ & 19 & 63,3 & 11 & 36,7 & 30 & 100,0 \\
\hline 5 & $\begin{array}{l}\text { Sasaran lansia yaitu penduduk yang } \\
\text { berumur } 50 \text { tahun ke atas. }\end{array}$ & 23 & 76,7 & 7 & 23,3 & 30 & 100,0 \\
\hline 6 & 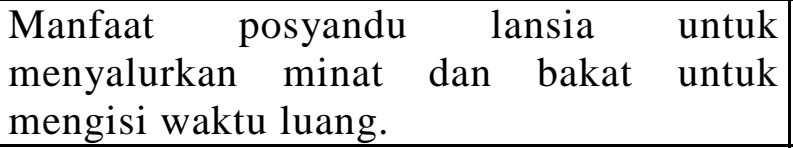 & 23 & 76,7 & 7 & 23,3 & 30 & 100,0 \\
\hline 7 & $\begin{array}{l}\text { Dalam posyandu lansia dilakukan } \\
\text { penyuluhan tentang gizi untuk lansia. }\end{array}$ & 22 & 73,3 & 8 & 26,7 & 30 & 100,0 \\
\hline 8 & $\begin{array}{l}\text { Kegiatan olahraga di posyandu lansia salah } \\
\text { satunya adalah senam lansia. }\end{array}$ & 23 & 76,7 & 7 & 23,3 & 30 & 100,0 \\
\hline 9 & $\begin{array}{l}\text { Posyandu lansia merupakan upaya untuk } \\
\text { mencegah terjadinya penyakit pada lansia. }\end{array}$ & 21 & 70,0 & 9 & 30,0 & 30 & 100,0 \\
\hline 10 & $\begin{array}{l}\text { Kegiatan posyandu lansia terdiri dari } 3 \\
\text { meja. }\end{array}$ & 16 & 53,3 & 14 & 46,7 & 30 & 100,0 \\
\hline
\end{tabular}

\section{2) Kategori Pengetahuan Sebelum dan Setelah Pendidikan Kesehatan}

Berdasarkan data menunjukkan bahwa sebelum diberi penkes tentang posyandu lansia, pengetahuan responden sebagian besar dalam kategori kurang sebanyak 18 orang $(60,0 \%)$, berpengetahuan cukup sebanyak 12 orang (40,0\%). Sesudah diberi penyuluhan, pengetahuan responden sebagian besar cukup sebanyak 22 orang $(73,3 \%)$, dan berpengetahuan baik sebanyak 8 orang $(36,7 \%)$.

Tabel 6 Distribusi Frekuensi Pengetahuan Responden Sebelum dan Setelah diberi Penkes di Desa Ujung Rambung Kecamatan Pantai Cermin Kabupaten Serdang Bedagai Tahun 2019

\begin{tabular}{|c|l|c|c|c|c|}
\hline \multirow{2}{*}{ No } & \multirow{2}{*}{ Pengetahuan } & \multicolumn{2}{c|}{ Sebelum } & \multicolumn{2}{c|}{ Sesudah } \\
\cline { 3 - 6 } & & f & \% & f & \% \\
\hline 1 & Baik & 0 & 0,0 & 8 & 26,7 \\
2 & Cukup & 12 & 40,0 & 22 & 73,3 \\
3 & Kurang & 18 & 60,0 & 0 & 0,0 \\
\hline \multicolumn{2}{|c|}{ Jumlah } & $\mathbf{3 0}$ & $\mathbf{1 0 0 , 0}$ & $\mathbf{3 0}$ & $\mathbf{1 0 0 , 0}$ \\
\hline
\end{tabular}




\section{Tindakan Pemanfaatan Posyandu Lansia}

Berdasarkan data menunjukkan bahwa sebelum diberi pendidikan kesehatan tentang posyandu lansia, sebagian besar lansia tidak aktif sebanyak 20 orang $(66,7 \%)$, yang aktif sebanyak 10 orang $(33,3 \%)$. Sesudah diberi penyuluhan, sebagian besar responden menjadi aktif sebanyak 21 orang $(70,0 \%)$, dan yang tidak aktif sebanyak 9 orang $(30,0 \%)$.

Tabel 7 Distribusi Frekuensi Tindakan Pemanfaatan Posyandu Lansia oleh Responden Sebelum dan Setelah diberi Penkes di Desa Ujung Rambung Kecamatan Pantai Cermin Kabupaten Serdang Bedagai Tahun 2019

\begin{tabular}{|c|l|c|c|c|c|}
\hline \multirow{2}{*}{ No } & Tindakan Pemanfaatan & \multicolumn{2}{|c|}{ Sebelum } & \multicolumn{2}{c|}{ Sesudah } \\
\cline { 3 - 6 } & Posyandu Lansia & f & \% & f & \% \\
\hline 1 & Aktif & 10 & 33,3 & 21 & 70,0 \\
2 & Tidak aktif & 20 & 66,7 & 9 & 30,0 \\
\hline \multicolumn{2}{|c|}{ Jumlah } & $\mathbf{3 0}$ & $\mathbf{1 0 0 , 0}$ & $\mathbf{3 0}$ & $\mathbf{1 0 0 , 0}$ \\
\hline
\end{tabular}

\section{Uji Statistik}

1) Pengaruh Pendidikan Kesehatan Terhadap Pengetahuan tentang Posyandu Lansia

Berdasarkan tabel di atas, menunjukkan bahwa nilai posttest pengetahuan lansia lebih tinggi dibandingkan nilai pretest. Nilai rata-rata (mean) pada pretest yaitu 3,57 sedangkan posttest yaitu 6,93, nilai tengah (median) pada pretest yaitu 3,00 sedangkan posttest yaitu 7,00, nilai simpangan baku (standar deviation) pada pretest yaitu 971 sedangkan posttest yaitu 944. Varians (variance) pada pretest 944 sedangkan pada posttest yaitu 892 .

Berdasarkan uji statistik menggunakan uji t dua sampel berpasangan (paired sample $t$ test) diperoleh nilai t-hitung $=-37,622>1,699$ (t-tabel) dan nilai $\mathrm{p}=0,000<0,05$ hal tersebut menunjukkan bahwa terdapat perbedaan pengetahuan lansia sebelum dan setelah diberikan pendidikan kesehatan tentang posyandu lansia atau terdapat pengaruh pendidikan kesehatan terhadap pengetahuan lansia di Desa Ujung Rambung Kecamatan Pantai Cermin Kabupaten Serdang Bedagai tahun 2019.

Tabel 8 Data Statistik Deskriptif Pretest dan Posttest Pengetahuan Lansia di Desa Ujung Rambung Kecamatan Pantai Cermin Kabupaten Serdang Bedagai Tahun 2019

\begin{tabular}{|c|c|c|c|c|c|}
\hline Pengetahuan & Mean & Median & $\begin{array}{c}\text { Standar } \\
\text { Deviasi }\end{array}$ & Varian & $\begin{array}{c}\text { Uji-t } \\
\text { (p-value) }\end{array}$ \\
\hline Sebelum (pretest) & 3,57 & 3,00 & 971 & 944 & \multirow{2}{t}{$=-37,622$} \\
$\mathrm{p}=0,000$
\end{tabular}

Keterangan: nilai $\mathrm{t}$ negatif $(\mathrm{t}=-37,622)$ menunjukkan bahwa nilai rata-rata pengetahuan lansia sebelum diberi penkes lebih rendah dibandingkan sesudah diberi penkes.

2) Pengaruh Pendidikan Kesehatan Terhadap Tindakan Pemanfaatan Posyandu Lansia

Berdasarkan tabel di atas, menunjukkan bahwa nilai posttest keaktifan lansia ke posyandu lansia lebih tinggi dibandingkan nilai pretest. Nilai rata-rata (mean) pada pretest yaitu 3,00 sedangkan posttest 4,13 , nilai tengah (median) pada pretest yaitu 3,00 sedangkan posttest 4,00, nilai simpangan baku (standar deviation) pada pretest 871 sedangkan posttest 900. Varians (variance) pada pretest 759 sedangkan pada posttest 809. 
Berdasarkan uji statistik menggunakan uji t dua sampel berpasangan (paired sample $t$ test) diperoleh nilai t-hitung $=-17,954>1,699$ ( $\mathrm{t}$-tabel) dan nilai $\mathrm{p}=0,000<0,05$ hal tersebut menunjukkan bahwa terdapat perbedaan tindakan pemanfaatan lansia sebelum dan setelah diberikan pendidikan kesehatan atau terdapat pengaruh pendidikan kesehatan tentang posyandu lansia terhadap tindakan pemanfaatan posyandu lansia di Desa Ujung Rambung Kecamatan Pantai Cermin Kabupaten Serdang Bedagai tahun 2019.

Tabel 9 Data Statistik Deskriptif Pretest dan Posttest Keaktifan Lansia Ke Poyandu di Desa Ujung Rambung Kecamatan Pantai Cermin Kabupaten Serdang Bedagai Tahun 2019

\begin{tabular}{|c|c|c|c|c|c|}
\hline $\begin{array}{c}\text { Pemanfaatan } \\
\text { Posyandu Lansia }\end{array}$ & Mean & Median & $\begin{array}{c}\text { Standar } \\
\text { Deviasi }\end{array}$ & Varian & $\begin{array}{c}\text { Uji-t } \\
\text { (p-value) }\end{array}$ \\
\cline { 1 - 4 } Sebelum (pretest) & 3,00 & 3,00 & 871 & 759 & \multirow{2}{*}{$\mathrm{t}=-17,954$} \\
$\mathrm{p}=0,000$
\end{tabular}

Keterangan: nilai t negatif $(\mathrm{t}=-17,954)$ menunjukkan bahwa nilai rata-rata pemanfaatan posyandu sebelum diberi penkes lebih rendah dibandingkan sesudah diberi penkes.

\section{Kesimpulan}

Berdasarkan hasil penelitian dengan judul "Pengaruh Pendidikan Kesehatan Tentang Posyandu Lansia Terhadap Tindakan Pemanfaatan Posyandu Lansia di Desa Ujung Rambung Kecamatan Pantai Cermin Kabupaten Serdang Bedagai Tahun 2019", dapat disimpulkan sebagai berikut :

1. Terdapat pengaruh (perbedaan) yang signifikan pengetahuan lansia sebelum diberikan pendidikan kesehatan (pretest) dengan pengetahuan sesudah diberi pendidikan kesehatan (posttest) dengan nilai t-hitung $=-37,622>1,699$ ( $\mathrm{t}$-tabel) dan nilai $\mathrm{p}=0,000<0,05$.

2. Terdapat pengaruh (perbedaan) yang signifikan tindakan pemanfaatan posyandu lansia sebelum diberikan pendidikan kesehatan (pretest) dengan tindakan pemanfaatan posyandu lansia sesudah diberi pendidikan kesehatan (posttest) dengan nilai t-hitung = $-17,954>1,699$ (t-tabel) dan nilai $\mathrm{p}=0,000<0,05$.

\section{Saran}

1. Tenaga Kesehatan (perawat) di Puskesmas Pantai Cermin

Diharapkan kepada tenaga kesehatan khususnya perawat aktif untuk memberikan pendidikan kesehatan baik kepada lansia maupun kepada anggota keluarga yang tinggal satu rumah dengan lansia agar pengetahuan pasien dan keluarga bertambah serta mampu melakukan perawatan pada lansia dengan semaksimal mungkin dan mendukung lansia untuk datang ke posyandu lansia.

2. Lansia

Diharapkan untuk banyak bertanya kepada petugas kesehatan tentang posyandu lansia serta manfaatnya sehingga lansia lebih termotivasi untuk memanfaatkan posyandu lansia.

3. Peneliti selanjutnya

Diharapkan melakukan penelitian lanjutan dengan menggunakan teknik atau metode penyuluhan (pendidikan kesehatan) yang berbeda seperti simulasi, diskusi, dan teknik lainnya yang dapat meningkatkan pengetahuan lansia untuk melengkapi hasil penelitian yang telah ada. 


\section{Referensi}

Darmayanti, F.N. 2012. Hubungan pendidikan kesehatan pada lansia dengan keikutsertaan lansia dalam posyandu lansia di kelurahan Sembungharjo kota Semarang. Abstrak.

Effendy, N. 2009. Keperawatan Kesehatan Masyarakat. Cetakan Pertama. Jakarta : EGC.

Fauzi, 2013. Agama dan Realittas Sosial. Renungan dan Jalan Menuju Bahagia. Jakarta : Raja Grafindo Perkasa.

Ismawati, Cahyo, dkk, 2010. Posyandu dan Desa Siaga, Cetakan Pertama. Jogjakarta : Sitra Medika.

Mubarak, W.I. 2010. Ilmu Kesehatan Masyarakat: Konsep dan Aplikasi Dalam Kebidanan. Jakarta: Salemba Medika.

Narulita, R.S. 2012. Pengaruh Pendidikan Kesehatan Terhadap Tingkat Pengetahuan Insomnia Pada Lansia.

Notoatmodjo, S. 2010. Ilmu Perilaku Kesehatan. Cetakan Pertama. Jakarta: Rineka Cipta.

Notoatmodjo, S. 2012. Kesehatan Masyarakat, Ilmu dan Seni, Cetakan I, Jakarta: Rineka Cipta.

Novayenni, R. 2015. Pengaruh Pendidikan Kesehatan Terhadap Angka Kunjungan Lansia Ke Posyandu Lansia. JOM Vol 2 No 1, Februari 2015.

Potter, A., 2012. Buku Ajar Fundamental Keperawatan : konsep, proses dan praktik. Edisi 4 volume 2. Jakarta: Penerbit buku kedokteran.

Prayitno, A., 2012. Gangguan Pola Tidur pada Kelompok Usia Lanjut dan Penatalaksanaannya, Bagian Jakarta: Ilmu Kesehatan Jiwa Fakultas Kedokteran Universitas Trisakti.

Rafknowledge, 2014. Insomnia dan Gangguan Tidur lainnya. Cetakan Kedua. Jakarta : Gramedia

Rafiudin R. 2014. Insomnia dan Gangguan Tidur lainnya. Cetakan Pertama. Jakarta : PT Elex Media Komputindo.

Rosidawati, 2008. Mengenal Usia dan Perawatannya, Cetakan Pertama. Jakarta: Salemba

Santoso, H., \& Andar, I. 2009. Memahami Krisis Lanjut Usia Uraian Medis Dan Pedagogis Patoral. Jakart: Gunung Mulia.

Setiabudi, T. 2012. Panduan Gerontologi. PT Gramedia Pustaka, Jakarta.

Setiadi, 2013. Konsep dan Proses Keperawatan Keluarga. Yogyakarta : Graha Ilmu.

Stanley, Mickey. 2013. Buku Ajar Keperawatan Gerontik, Edisi 2. EGC, Jakarta.

Sumedi, T., 2010. Pengaruh Senam Bugar Lansia Terhadap Penurunan Soedirman Skala Insomnia di Panti Wredha Dewanata Cilacap. Jurnal Keperawatan Soedirman (The Soedirman Journal Of Nursing), volume 5 No. 1 Maret 2010.

Tamher, S dan Noorkasiani, 2011. Kesehatan Usia Lanjut dengan Pendekatan Asuhan Keperawatan. Jakarta : Salemba Medika

Tarigan, E. 2009. Pengetahuan, Sikap dan Tindakan Lansia tentang Pemanfaatan Posyandu Lansia Dalam Menunjang Status Gizi Di Puskesmas Petisah Medan Tahun 2009. Skripsi FKM USU. Medan.

Walgito, B. 2013. Psikologi Sosial (Suatu Pengantar), Edisi Revisi, Yogyakarta: Andi.

Wawan dan Dewi. 2011. Teori Pengukuran Pengetahuan, Sikap dan Perilaku Manusia, Cetakan Kedua. Yogyakarta: Nuha Medika.

Aditama, T.Y. 2009. Tuberkulosis Paru, Masalah dan Penanggulangannya, Jakarta: Universitas Indonesia Press. 
2010. Tuberkulosis Paru, Diagnosa, Terapi dan Masalahnya, Edisi IV, Jakarta: Ikatan Dokter Indonesia.

Alsagaff Hood, Abdul Mukty, 2005. Dasar-Dasar Ilmu Penyakit Paru.. Surabaya: Airlangga University Press.

Amin, M., Hood Alsagaff, W.B.M. Taib Saleh, 2009. Pengantar Ilmu Penyakit Paru, Jakarta : Airlangga University Press.

Arikunto, S. 2010. Prosedur Penelitian Suatu Pendekatan Praktek. Cetakan II, Edisi 4, Jakarta : Rineka Cipta.

Dinkes Propsu. 2012. Profil Kesehatan Propinsi Sumatera Utara tahun 2011. medan: Dinas Kesehatan Propinsi Sumatera Utara..

Handayani, T.E. 2010. Pengaruh Pendidikan Kesehatan Terhadap Tingkat Pengetahuan Dan Sikap Masyarakat Tentang Pencegahan Tuberkulosis Paru Di Dusun Kayangan Kecamatan Karanganyar Kabupaten Karanganyar. Jurnal Penelitian.

Kemenkes RI. 2011. Strategi Nasional Pengendalian TB Di Indonesia 2010-2014. Kementerian Kesehatan Republik Indonesia Direktorat Jenderal Pengendalian Penyakit dan Penyehatan Lingkungan.

Priyatno, D. 2009. Mandiri Belajar SPSS. Cetakan Ketiga, Jakarta: Buku kita.

Rifai, T.S. 2005. DOTS di Rumah Sakit, Jakarta : Puspaswara.

Smeltzer and Bare. 2008. Buku Ajar Keperawatan Medikal Bedah. Jakarta: Buku Kedokteran EGC.

Sulaiman, \& Anggriani. (2018). PkM Pemanfatan Posyandu lansia Di Desa Sukaraya Kecamatan Pancurbatu Tahun 2017. AMALIAH: JURNAL PENGABDIAN KEPADA MASYARAKAT, 2(1), 161-164. https://doi.org/10.32696/ajpkm.v2i1.109

Sulaiman, S., Anggriani, A., \& Sutandra, L. (2019). Sosialisasi Pemberian Infrared dan Tens pada Lansia di Desa Sukasari, Serdang Bedagai. Jurnal Pengabdian Pada Masyarakat, 4(2 SE-Articles). https://doi.org/10.30653/002.201942.128

Taufik, M. 2007. Prinsip-Prinsip Promosi Kesehatan Dalam Bidang Keperawatan, Untuk Perawat dan Mahasiswa Keperawatan, Cetakan Pertama, Jakarta: Infomedika. 